\section{Immunoglobulin E-Mediated Severe Allergy to Hyoscine Butylbromide}

Mendez Diaz $\mathrm{Y}^{1}$, Gómez Torrijos $\mathrm{E}^{1}$, Moreno Lozano $\mathrm{L}^{1}$, Extremera Ortega $\mathrm{AM}^{1}$, García Rodríguez $\mathrm{R}^{1}$, Hornos López $\mathrm{MC}^{2}$, Pineda de la Rosa $\mathrm{F}^{3}$, Borja Segade $\mathrm{J}^{1}$

${ }^{1}$ Allergology Service, Hospital General Universitario, Ciudad Real, Spain

${ }^{2}$ Intensive Care Unit, Hospital General Universitario, Ciudad Real, Spain

${ }^{3}$ Diater Laboratory, Leganés, Spain

J Investig Allergol Clin Immunol 2018; Vol. 28(4): 255-254 doi: 10.18176/jiaci.0247

Key words: Hyoscine butylbromide. Kounis syndrome. Allergy. Anaphylactic reaction. IgE-mediated hypersensitivity.

Palabras clave: Bromuro de hioscina. Síndrome de Kounis. Alergia. Reacción anafiláctica. Hipersensibilidad mediada por lgE.

Hyoscine butylbromide is an antispasmodic cholinergic agent with a quaternary ammonium structure [1]. Kounis syndrome (KS) is an acute coronary syndrome during an allergic anaphylactic reaction. It is classified into 3 variants [2]:

- Type I, without coronary heart disease, in which the allergic reaction leads to coronary vasospasm.

- Type II, with coronary disease, in which the acute release of mediators leads to the rupture of a preexisting atheromatous plaque

- Type III, in which the allergic event leads to pharmacoactive stent thrombosis.

A 51-year-old man received $20 \mathrm{mg}$ of hyoscine butylbromide, $2 \mathrm{~g}$ of metamizole, $10 \mathrm{mg}$ of metoclopramide, and $40 \mathrm{mg}$ of pantoprazole for biliary colic. Ten minutes after endovenous administration of the drugs, the patient complained of epigastric pain, sweating, sickness, and vomiting and presented loss of consciousness, hypotension $(58 / 30 \mathrm{mmHg})$, ST-segment elevation on the inferior heart wall, and cardiorespiratory arrest. No skin symptoms were observed. After being stabilized, the patient was admitted to the intensive care unit (ICU) for orotracheal intubation and mechanical ventilation. Owing to the persistence of abdominal pain a further dose of $20 \mathrm{mg}$ of hyoscine butylbromide was administered; macular exanthema appeared immediately on the face and trunk.

The ECG performed in the emergency room showed a 5-mm ST-segment elevation on the inferior heart wall and a decreased ST-segment in V2-V3, I, and aVL. Serum troponin was elevated $(0.54 \mathrm{ng} / \mathrm{mL})$.

Twenty-four hours after admission, ECG abnormalities had resolved and troponin levels returned to normal values.

All the cardiological tests performed showed normal results. Contractility alterations were not found in echocardiography, the thoracic CT angiogram ruled out acute aortic syndrome, and coronary angiography showed normal coronary arteries.
The allergology study revealed the following results: positive skin prick test (SPT) to hyoscine butylbromide at $20 \mathrm{mg} / \mathrm{mL}(5 \times 3-\mathrm{mm}$ papule diameter $)$ and negative at $0.4 \mathrm{~g} / \mathrm{mL}$ to metamizole. SPT with hyoscine butylbromide was performed in 3 atopic and nonatopic patients, with negative results. Histamine phosphate $(10 \mathrm{mg} / \mathrm{mL})(5 \times 7$ $\mathrm{mm}$ ) was used as a positive control and saline $(0.9 \%)$ as a negative control.

Intradermal tests (ID) with $1 / 100$ metamizole and $1 / 10$ metamizole were negative.

The patient refused to undergo challenge with metamizole. The results of challenge tests (CT) with pantoprazole and metoclopramide were negative.

The eosinophil count in peripheral blood was normal (110 eosinophils $/ \mu \mathrm{L})$, as was basal serum tryptase $(4.5 \mu \mathrm{g} / \mathrm{L})$. Specific IgE to hyoscine butylbromide could not be determined, because the test is not commercially available.

The basophil activation tests (BAT) with hyoscine butylbromide at $1 / 100,1 / 10$, and undiluted were negative.

Passive sensitization with hyoscine butylbromide $20 \mathrm{mg} /$ $\mathrm{mL}$ in the histamine release test was positive $(10 \mathrm{ng} / \mathrm{mL}$ of histamine released 10\%) (Figure).

KS can manifest as coronary spasms, acute myocardial infarction, or stent thrombosis. Although this clinical entity is well-documented, there are many unanswered questions regarding its etiology, pathophysiology, and treatment [3]. In addition, while not rare, KS is infrequently diagnosed [4].

Diagnosis is based on symptoms and suggestive signs of an acute allergic reaction simultaneously with acute coronary syndrome (angina, vegetative symptoms) related to previous contact with a possible allergen $[4,5]$. The patient we report, who had no coronary risk factors, had presented 2 episodes of epigastric pain with bilious vomiting during the previous 6 months. On those occasions, ECG did not reveal myocardial ischemia, and serum troponin was within the normal range. The diagnosis was uncomplicated biliary colic. At the last visit for abdominal pain, empirical analgesic treatment was started after an ECG perfomed to rule out cardiac angina in the emergency department before drug infusion.

Therefore, the sudden onset of symptoms of acute coronary syndrome and ST-segment elevation associated with increased troponins after treatment with various drugs, together with an echocardiogram with no contractility alterations, led us to suspect type I KS.

In the absence of a commercial test to determine specific $\operatorname{IgE}$ to hyoscine butylbromide, a dot-blot was performed with the patient's serum against hyoscine butylbromide and metamizole, although the results were negative. In the release of histamine via passive immunization, specific $\operatorname{IgE}$ binds to the IgE receptor of the healthy donor basophil. After stimulation with the reagents, histamine release was significant and probably IgE-mediated [6]. Given these results, the positive skin test with hyoscine butylbromide, the positive reexposure with hyoscine butylbromide in the intensive care unit, and the histamine release test result, we considered that hyoscine butylbromide was the most probable culprit drug, with a high probability of an IgE-mediated mechanism. The normal basal tryptase levels ruled out mast cell activation syndrome [7]. 


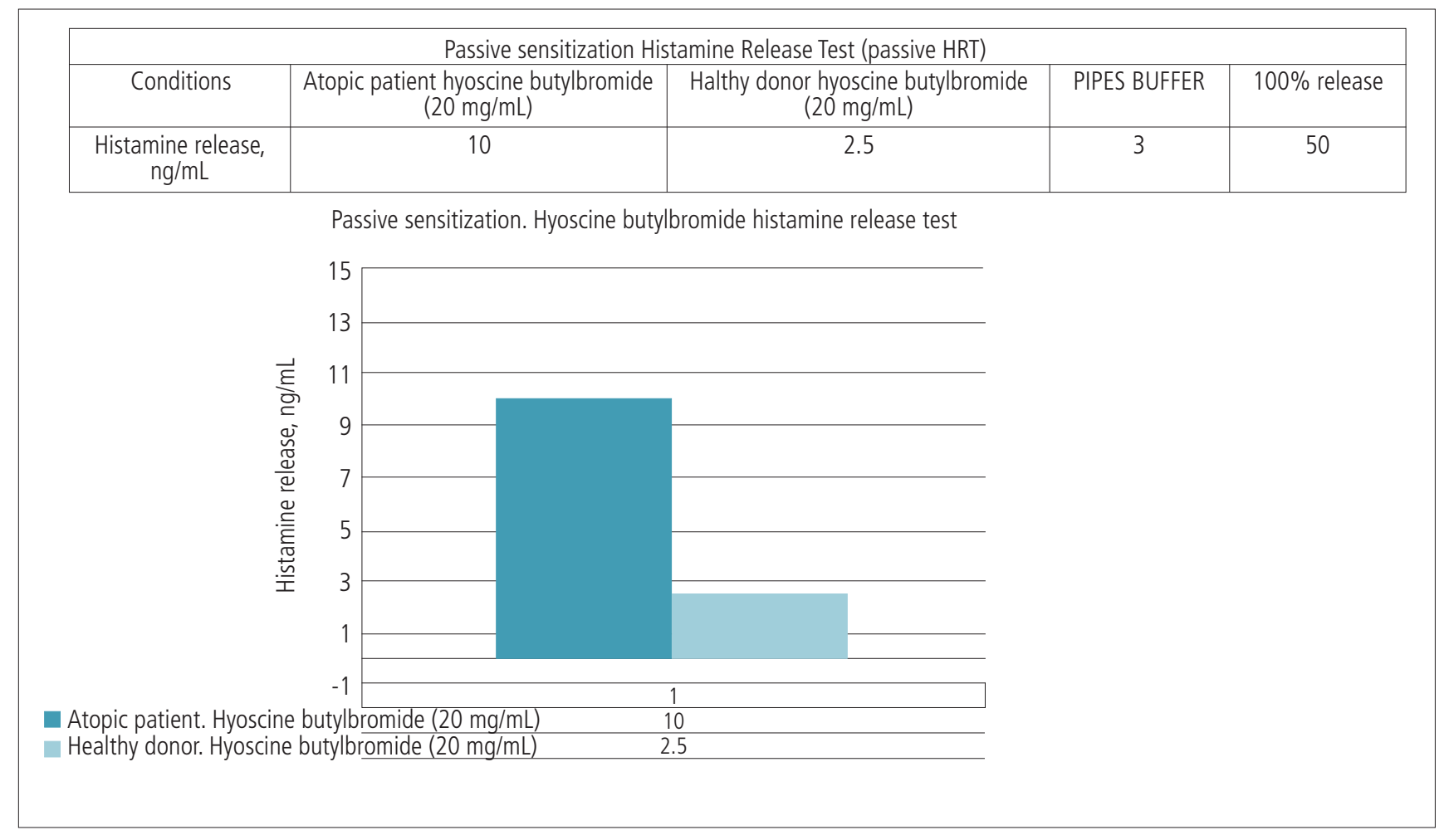

Figure. Histamine release test (hyoscine butylbromide).

Reexposure to hyoscine butylbromide in the intensive care unit was performed 24 hours after onset of the clinical picture, when the patient was receiving vasoactive drugs. The infusion of hyoscine butylbromide was not completed because of cutaneous exanthema. Therefore, it does not seem likely that a new episode of anaphylaxis and acute coronary syndrome was triggered.

We cannot exclude hypersensitivity to metamizole as the main etiology of KS owing to the absence of a CT scan (gold standard test). Similarly, we cannot exclude the possibility of further exanthema due to sensitization to hyoscine butylbromide (double sensitization).

Although hyoscine butylbromide is widely used, very few associated hypersensitivity reactions have been reported. González-Mendiola et al [8] reported a case of urticaria with positive skin and challenge tests to hyoscine butylbromide. Thirty years ago, another possible reaction manifesting only with bronchospasm was attributed to hyoscine butylbromide, although the patient did not undergo allergy testing. Angioedema and urticaria have been reported in a patient treated with hyoscine butylbromide; the authors suggested an IgE-mediated mechanism based on the patient's symptoms, although they did not perform an allergy study [9]. A case of sudden death due to intramuscular hyoscine butylbromide was reported in a patient with significant elevated serum tryptase $(100 \mathrm{mg} / \mathrm{L})$, thus indicating that death was due to type I allergy to this drug [10].

We report the first case of severe type I KS probably caused by an IgE-mediated hypersensitivity reaction to hyoscine butylbromide.

\section{Funding}

The authors declare that no funding was received for the present study.

\section{Conflicts of Interest}

The authors declare that they have no conflicts of interest.

\section{References}

1. Tytgat GN. Hyoscine butylbromide: a review of its use in the treatment of abdominal cramping and pain. Drugs. 2007;67(9):1343-57.

2. Abdelghany M, Subedi R, Shah S, Kozman H. Kounis syndrome: A review article on epidemiology, diagnostic findings, management and complications of allergic acute coronary syndrome. Int J Cardiol. 2017;232:1-4.

3. Kotsiou OS, Xirogiannis KI, Gourgoulianis KI. Kounis Syndrome: Is it Really a Takotsubo-Like Syndrome? J Investig Allergol Clin Immunol. 2017;27(3):198-200

4. García Núñez I, Algaba Mármol MA, Barasona Villarejo MJ, Suárez Vergara M, Espínola González F, Reina Ariza E. Kounis Syndrome After Levofloxacin Intake: A Clinical Report and Cross-reactivity Study. J Investig Allergol Clin Immunol. 2016;26(5):335-6.

5. Rodríguez-Serrano DA, Torrejón-Péreza I, Abella-Álvareza A, Elices A. Síndrome de Kounis tipo I. Rev Clin Esp. 2012;212:472-3.

6. Arribas F, Falkencrone S, Sola J, Gomez-Serranillos MP, Laguna JJ, Montañez MI, et al. Basophil histamine release 
to Amoxicilloyl-poly-L-lysine compared to amoxicillin in patients with IgE-mediated allergic reactions to amoxicillin. J Investig Allergol Clin Immunol. 2017 Jun 19:0. doi: 10.18176/ jiaci.0180. [Epub ahead of print]

7. De la Fuente Tornero E, Vega Castro A, de Sierra Hernández PÁ, Balaguer Recena J, Zaragoza Casares SC, Serrano Baylin FM, et al. Kounis Syndrome During Anesthesia: Presentation of Indolent Systemic Mastocytosis: A Case Report. A Case Rep. 2017;8(9):226-8.

8. González-Mendiola R, Sánchez Fernández C, Prieto Montaño $P_{1}$ Cuevas M, Delgado Ceña M, Sánchez Cano M. Acute urticaria induced by hyoscine butylbromide. Allergy. 2004;59:787-8.

9. Robinson AC, Teeling $M$. Angioneurotic oedema and urticaria induced by hyoscine butylbromide. Postgrad Med J. 1982;58(679):316.

10. Ikegaya H, Saka K, Sakurada K, Nakamura M, Yoshida K. A case of sudden death after intramuscular injection of butylscopolamine bromide. Leg Med. 2006;8(3):194-7.

1. Manuscript received September 7, 2017; accepted for publication February 27, 2018.

Elisa Gomez Torrijos

Hospital General Universitario de Ciudad Real C/ Obispo Rafael Torija s/n 13005 Ciudad Real, Spain E-mail: egomezt.cr@gmail.com jmborjaseg@gmail.com 